\title{
Analysis of Information Literacy on Diffable Students
}

\author{
Setiawan ${ }^{1}$, Moch. Syahri ${ }^{2}$, Reza Fawzia Ahmad ${ }^{3}$, Fatmawati Dhuhriyyah ${ }^{4}$ \\ \{setiawan@um.ac.id ${ }^{1}$ \} \\ Faculty of Letter, State University of Malang, Indonesia ${ }^{1,2,3,4}$
}

\begin{abstract}
The purpose of this study is to find out literary analysis information on students with disabilities at the State University of Malang.In this current study, a descriptive qualitative approach was applied as the research method. Descriptive qualitative research is research used to gain insight into an issue/problem in a natural setting. During the study, the researchers focused on analyzing the information literacy of students with disabilities that are based on their psychological condition, cognitive, and demographic. The results of this study were found analysis literacy in the context of information needs; the students need information according to the field they are studying. They have an interest in other fields such as music, sports, chess, and tend to seek information in accordance with that field. In the context of information literacy analysis based on information-seeking behavior on students with disabilities, they already have a need, and they do a search, the media used is the internet. From the aspect of information processing and use, it is found that they evaluate the information.Suggestion for further researchers or other researchers, it is hoped that the results of this study can be used as a reference or source in conducting research related to information literacy in students with disabilities.
\end{abstract}

Keywords: Information literacy, diffable

\section{Introduction}

\subsection{Background}

The increasing of education quality is in line with the increasingly advanced times, the efforts made by the government are continuously encouraged and enhanced so that the community can master the aspects of knowledge. One of the basic efforts completed by the government is to grow and increase the reading curiosity of the community. Fostering and increasing the reading interest of society also has many dilemmas because of the different abilities of everyone in society. For that reason, various efforts have been developed by the government, one of them is the national literacy movement, but literacy does not automatically succeed in growing and increasing the ability of reading awareness, it takes a long process to eradicate low literacy.

The results of the assessment by the Programme for International Student Assessment (PISA) show that in 2015 Indonesia is still in the top 10 of the lowest rank, specifically 62 out of 72 countries with an average score of 395 . There is a fascinating point from the three aspects of literacy, namely reading, math skills, and science skills which have been increased from the previous year in 2012. "Our literacy level is still low; it can be realized from the PISA score which is still below the average of OECD countries. Our PISA score even lost to Vietnam". Meanwhile, according to the Indonesian National Assessment Programme (INAP) in 2016, the 
literacy condition in the community in terms of reading ability was $46.83 \%$ which is included in the low category.

One of the government programs that often carried out by schools is the school literacy movement program or also the information literacy movement. Information literacy can be defined as a person's ability to read and write something that is being discussed, heard, and expressed. There are various definitions of literacy which proportional to the development of human knowledge and science as well as its results. Information literacy has a concept originating from the United States, containing the explanation that it is essentially used to respond to the uncontrolled growth from its quality and quantity. This definition has been debated by information experts, especially the contention regarding the use of the term "information literacy". The term information literacy is not always acceptable, such as Carbo who proposed the term information media. Meanwhile, Goestch and Kaufman in SulistyoBasuki use the term information competency for the term information literacy. In this book, the author uses the term information literacy in the direction of facilitating an understanding of information literacy [1].

The literacy components that are carried out, as follows (1) Early Literacy, the actions of early literacy are listening, understanding spoken language, and communicating through pictures and speech which formed by the experience of interacting with the social environment at home. (2) Basic Literacy, the ability to listen, speak, read, write, and count (counting) is related to the ability of analysis to take into account (calculating), perceive information (perceiving), communicate, and describe information (drawing) based on understanding and personal conclusion. (3) Library Literacy is the ability to comprehend how to differentiate the reading of fiction and nonfiction, utilize reference collections and periodicals, understand the Dewey Decimal System, use catalogs and indexes, have the knowledge to understand the information while completing a paper, study, work, or overcome problems. (4) Media Literacy, the aptitude to recognize the various form of media such as printed media, electronic media (radio media, television media), digital media (internet media), and understand their intended use. (5) Technology Literacy is the capability to understand the equipment that follows technology, such as hardware, software, ethics, and etiquette in utilizing technology. The ability to comprehend technology for printing, presenting, and accessing the internet. (6) Visual Literacy is an advanced understanding between media literacy and technology literacy by operating the visual materials and the audio-visual critically and with dignity.

Not a mere given to normal people, information literacy activities can be used or applied to people who have special needs (diffable) as well, because basically, they can absorb information just like any normal human being, but the problem is how we accomplish the need of information literacy for them (diffable). From the data obtained, there are about 40 students with disabilities at the State University of Malang. For this reason, the researcher decided to do research or analysis of information literacy on students with disabilities at the State University of Malang.

The research problem of this study is "How is The Information Literacy Analysis for students with disabilities at the State University of Malang?". The research objective of this paper is identify the analysis of information literacy on students with disabilities at the State University of Malang. Practically, the result of this study can determine the analysis of information literacy on students with disabilities at the State University of Malang.

\subsection{Review of related literature}

\subsubsection{Information literacy}


According to Johnston and Webber [2], information literacy is an accumulation of the proper information behavior by utilizing the media and the channel in any form, as well as applying critical thinking skill to get the information in accordance with the information requirements. Based on this definition, the researchers used a behavioral model developed by TD. Willson to analyze the information literacy condition of the students with disabilities. This model was chosen because it can present the overall information behavior of an individual and explain the external and internal motivations behind the appearance of such information behavior.

This model is applicable in analyzing information literacy of disabled students because it can provide the data on how their diffability affects the psychological and individual cognitive condition, and how the interaction with the social environment also affect the individual information behavior which will eventually affect their level of information literacy.

Wilson described the information behavior model using a cycle in which one aspect is interconnected with another. A person's information behavior is first triggered by the need for information. A person who has this information need does not immediately realize their information need or changes their information need into information behavior. Information needs are realized when a person understands the pressure and life problems experienced, and the information that they have cannot be used yet to solve the problems. Afterward, information needs will change to information behavior when a person considers internal factors related to what risk will be obtained when they fulfill or do not fulfill their information needs [3].

The following Fig. 1 shows the information behavior model by TD. Wilson that used in this study:

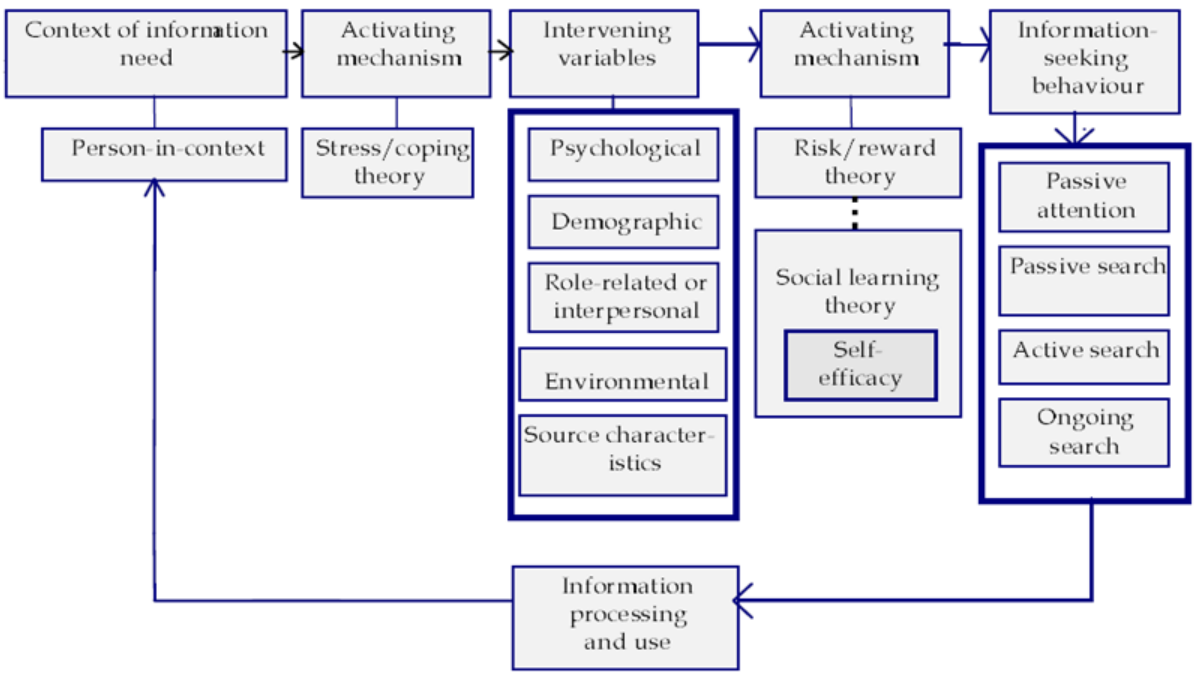

Fig. 1. Wilson 1996 model of information behavior[4]

Furthermore, individuals will also consider the external factors to decided that they will change their information needs into information behavior. Alluding to Wilson [4], some aspects can influence the information behavior of the individual, as follows:

\subsubsection{Demographic (demographic)}


A person's demographic condition is related to the data population. The demographic condition of a person contain gender, age, education, origin, location/area of residence, nationality, and others. Someone who has an undergraduate education certainly has a different behavior from a high school graduate. Likewise related to the location of residence. If someone lives in a mountainous area far from the internet connection, obviously that person will only rely on certain information sources (books, magazines, newspapers, television) in their information behavior. Unlike someone who lives in a city or an area that can reach the internet connection will have a different information behavior in satisfying their information needs.

\subsubsection{Role-related or interpersonal (one's role in society)}

A person's role in society will affect that person's information behavior. A person's role will also have an impact on the personal and interpersonal relationships in society. For example, the head of the neighborhood must have a more complex information behavior than ordinary people. The head of the neighborhood needs comprehensive information; therefore, it affects the information behavior that is carried out. A librarian and student also have different information behavior in fulfilling their information needs. If a librarian deals with more complex sources of information and know-how to trace and find out the information appropriately, a student might not be able to do the same thing because of the limited abilities and knowledge.

\subsubsection{Environment (environment)}

A condition that exists around the individuals can give an impact on their information behavior directly or indirectly. In this case, the environment has an extensive sense, it can be interpreted as a work environment, socio-cultural, economic, and political [4].

Besides the five factors above, information behavior is also influenced by risk factors and rewards obtained in browsing the information. At this point, a person will think twice about doing something, especially regarding information search and discovery. It is certainly adjusted to the existing condition of everyone. Pendit [3] provides an example related to this case, for instance, a well-known scientist felt he would look stupid in front of a librarian. This is quite different when compared to the lecturers who do not maintenance about their image ahead of the librarian. The scientists may feel prestige when asking the librarians, but the lecturers might do not care because they will get the appropriate rewards or benefits from questioning the librarians.

The next step of this model is information-seeking behavior. People have various behavior in searching for information, some act with passive attention, for example, looking around or doing a simple observation. There is also a person who acts as a passive seeker by asking friends or browsing carelessly. Not a mere acting as the passive seeker, some of them do an active search by looking for information that has in accordance with what they want and then comparing the information they get. Furthermore, they also have reached the advanced search stage, for instance, using advanced search, Boolean operator, and others. In conclusion, each individual certainly has a different way of searching for information.

The final step is the processing and the use of information to solve the problem faced by individuals, when the information is used, it will bring up the other need for information. Therefore, the process is still going on continuously.

\subsubsection{Diffable}


Arif Maftuhin stated that diffable or differently-abled is a concept which used to describe the individual with different abilities, in which these people are not like they cannot do something, but they do it in a different way [5] Based on Law number 4 of 1997 on disabilities, it states that disabilities are divided into three categories, namely physical, mental, and multiple. Physical contains the body, deaf, and blind, while mental consists of mental retardation and expsychotic disabilities. Mental retardation is someone who has different development between their mental and biological, meanwhile, ex-psychotic is someone who has experienced mental disorders.

Research which is conducted by Hastuti, et al shows that people with disabilities have a low information literacy level, it occurs due to several factors, as follows a) the lack of access to information technology. Based on the data, it is discovered that only $55.28 \%$ of people with disabilities have access to information technology and the internet. Even for people with severe disabilities, only $16.08 \%$ of them who has access to the internet. b) the minimal use of sign language, braille, and augmentative communication. Besides the access to information in the form of technology, the right to information in the form of sign language, braille, and augmentative communication in several official activities also have not been obtained. The awareness of activity organizers regarding the information accessibility for people with disabilities is still deficient. c) high illiteracy percentage among people with disabilities. In 2018 , $99.28 \%$ of Indonesia's population was literate, but, if it is looked more closely, the literacy rate for people with disabilities is below that number or about $87.63 \%$ [6].

Low level of information literacy influences the low access to education, health, and profession. In the education sector, it was found that only $40.51 \%$ of people with disabilities have an elementary school certificate, the number of special schools is also limited. In 2015 , the data shows that out of 1.5 million children with disabilities, only 55.836 of them received education. Meanwhile, in the health sector, people with disabilities unable to get quality health services because most of them are in the middle to lower class economy. The last one is related to profession, many people with disabilities have low education, therefore, they are generally cannot get a decent wage job and most of them earn below the minimum wage [6].

\section{Method}

The research methodology of Information Literacy analysis on Diffable Students used a descriptive qualitative approach. Descriptive qualitative research is a research that used to gain a depth understanding of an issue/problem in its natural setting, where during the study the researcher analyzed the information literacy of diffable students based on their psychological, cognitive, and demographic conditions. This study used various of data sources so that researchers can develop a comprehensive picture of the problems/issues being studied [7]. In line with this, the target in this study is not the measurement, but in-depth understanding and analysis of student's information literacy in its natural setting.

\section{Result and Discussion}

\subsection{Result}

\subsubsection{Data informant}


The data (Table 1) informants of this study were 10 difabble students who studying at the State University of Malang. Based on the table of the data informants which are diffable students of State University of Malang, $70 \%$ are male and $30 \%$ are female.

Table 1. Diffable students

\begin{tabular}{|c|c|c|}
\hline No. & Gender of Diffable Informant & Percentage \\
\hline 1. & Male & $70 \%$ \\
\hline 2. & Female & $30 \%$ \\
\hline & Total & $100 \%$ \\
\hline
\end{tabular}

The Table 2 below describes the data informants based on the type of difable. The data show that $40 \%$ of them are blind, $30 \%$ are deaf, $20 \%$ are quadriplegic, and $10 \%$ other means that they also have the type of diffable, namely paralysis, spinal cord narrowing, autism

Table 2. Types of diffable

\begin{tabular}{|c|c|c|}
\hline No & Type of Diffable & Percentage \\
\hline 1 & Deaf & $30 \%$ \\
\hline 2 & Blind & $40 \%$ \\
\hline 3 & Quadriplegic & $20 \%$ \\
\hline 4 & Etc & $10 \%$ \\
\hline & Total & $100 \%$ \\
\hline
\end{tabular}

Based on the informant's answer (diffable people) regarding to the respond of people around them towards their presence, the researchers found that people around the diffable can understand, kind, and help them to face their difficulties, but there are also some informants who say that the people around them have a lack of understanding, misinterpreted, or even do not care about them.

\subsubsection{Context of Information needs}

Alluding to the context of information needs of diffable students at the State University of Malang, 10 informants answered simultaneously that they have an interest toward certain fields. Furthermore, in terms of looking for information related to that field (which you tend to look for/like) they simultaneously answer "yes" which means that they have an interest to certain fields and they definitely will do a search related to the fields they are looking for.

\subsubsection{The mechanism of activation 1}

"I want to be a useful person, help my diffable friends, and be able to make my parents proud" (MG/W/ 01/09/2020).

From the informant statement above, it was very clear that in this first activation, most of the informants stated that they want to be useful, help diffable friends and make the parents proud, these three things are the highest answer of the informants. Even with their limitations, they still have high expectations.

The second answer obtained from the results of their interview; they had a hope that the available information could help the informants in overcoming all the existing problems.

"Wish this information can help me" (IG/W/05/09/2020) 
The statement above was in accordance with the answer from one of the informants.

"Information is sought based on the problems that we experienced, for example, the economic program that we are currently experiencing, so we tend to look for information about how the solution of this situation can be connected to any business that can be done in the present era. Therefore, confidently the information that are looking for needs to be considered and when the information is looking for obviously the information is needed "(IM/W/27/09/2020) skill).

The third answer is they have high motivation, which is they want another ability (soft

"My motivation is to increase my life skills and to be taught again to others" (EC / W / 26/09/2020)

From several answers, there were informants who stated that their motivation was not directly answering but firstly they sought the truth of the information.

"Looking for the truth from these sources" (GA/W/01/09/2020)

One respondent with the initials AS stated that their motivation was because they have a curiosity in interesting things

"Usually out of curiosity" (AS/W/28/09/2020)

\subsubsection{Intermediate variable}

In this section, to facilitate initial identification, which is related to age, where it comes from, education, gender, pocket money, the involvement in the organization, the role in the organization, whether the role in the organization affects the seeking-information behavior, how these special needs affect the way you search for information, how the people around you treat you (related to your disabilities), the respond of other people affect information-seeking behavior based on the age factor. three informants were 20 years old; three informants were 22 years old. two people are 21 years old, one person is 21 years, and one person is 25 years old, it reflects the informant data in terms of informant age which is more heterogeneous in terms of their age.

From the city of origin, these diffable students come from various regions, from Malang, Bali, Jombang, Kalimantan, Surabaya, Sidoarjo. Even though they were from different cities, their intention to learn and seek knowledge was still carried out with enthusiasm despite their condition. it could be seen from the data interview, the researchers found their place in the city of origin even though they are mostly from urban areas, they also came from remote areas as revealed by them.

The level of education taken by the informants at this time mostly took the undergraduate level at the State University of Malang, then 1 person took the diploma level at the State University of Malang, it showed that their awareness of the level of education, they were trying to make them not inferior to normal people in general.

"I'm currently studying undergraduate, and just graduated from high school" (MG, GA, IG, EC, IM, USA, JP, AZ, RK/W/28/09/2020).

Meanwhile, only one informant has a diploma education

"I am studying in diploma of Fashion Design" (EN/ W/01/10/2020)

Whereas for revenues or allowances in a month, the informants have various answers, most of them or about five informants, got pocket money or an income less than one million rupiah.

"I get a revenue of two hundred thousand rupiah/month" MG/W 01/10/2020)

"I get an allowance of three hundred thousand rupiah/month" (GA/ W / 25/09/2020)

From the income variation, it was also found that there were two informants who answered uncertain in this matter, especially since the condition of the nation is affected by Covid 19. 
"It is uncertain, especially when it is currently experiencing a crisis because of the Covid 19 pandemic" (EC/W/26/09/2020)

\subsubsection{The mechanism of activation two}

The activation mechanism carried out by researchers was what do you consider when deciding to find/not find the information, based on your previous information-seeking experience, did you always find the information you need, If the information was used, can it solve the problems that you were facing.

The consideration of deciding whether to seek or not to seek information, five informants stated that they needed this information.

"Needs (task and requirements to seek related information) (EC, IM, AZ, RK, EN / $\mathrm{W} / 28 / 09 / 2020)$.

\subsubsection{Behavior of information searches}

Behavior of the search for information carried out by diffable student informants at the State University of Malang were described in the following interview, the researcher did the questioning instrument related to these things, as follows

How the trend of the behavior of the search for information and what media did you use to find the information.

The tendency of the behavior of information searches from diffable students of the State University of Malang found some data from informants, as many as five respondents stated that they already knew the information needs and then carried out information searches, the point here was that they already know what the informants want, from this need arose a desire to search for the desired information. The answers were as follows

"Has already known the need for information, then do an information search" (EN, AZ, JP, EC, GA/W/28/09/2020)

Then there were 3 informants who stated that the tendency for the behavior of information search was that they carried out continuous information searches (there were certain topics that were followed) such as when they were doing the lecture assignments, they had already existing topics, just how they looked for that information.

The media used in information retrieval by diffable informants/students of the State University of Malang is one of the important media, it was found that 9 informants stated that the media that often used was the Internet.

"The medium that I used was the internet" (MG, GA, IG, EC, IM, US, JP, AZ, EN/W/01/10/2020).

\subsection{Discussion}

\subsubsection{Context of information needs}

From the context of information needs, informants stated that they really need this information even with the existing limitations, according to Wilson's theory a person's behavior of information was triggered by information needs. They required the information, then from 
the information needs arose behavior of information, among the information they were looking for information based on the field that has studied.

\subsubsection{The mechanism of activation one}

After knowing the activities that have an effect on the emergence of information needs, the next step was to analyze the mechanism of activation. The mechanism of activation in Wilson's information behavior model spawns two times. The first activation mechanism was created after the context of information needs which attempts to explain how the process of information needs may or may not change. The first activation, the researchers conducted interviews with informants which was related to when diffable students were aware for information needs, what motivation was taken by them into consideration to decide whether the information has been sought or not, most of the answered that there is a desire to solve the problem.

\subsubsection{Intermediate variable}

In the intermediary variable, the researcher wanted to describe how the conditions and circumstances of the informants of diffable students of the State University of Malang. In average, the circumstance of diffable students, most of them were students in Undergraduate program (S1) although their economic level was not same between one and other. The place of origin was also heterogeneous which came from various regions in East Java. The intermediate variable intends to find out whether the diffable students want to achieve the information needs and how the behaviors of diffable students. The intermediate variables can open the perceptions of the informants which means that this intermediate variable did a cross-check whether the behaviors towards the information needs have relation with the condition of the diffable students.

\subsubsection{The mechanism of activation two}

The appearance of a second activation mechanism came after the intervention variable which explained the theory of risk and reward along the motivation for achieving success. The theory of risk and reward in Wilson's theory was related to the search for information and what rewards will be obtained from the surrounding environment and from within oneself (motivation for success) [8].

\subsubsection{Behavior of information searches}

The tendency of behavior of information searches from diffable students of the State University of Malang found some data from informants which most of them stated that they already knew the information needs and then carried out information searches. At this point, they have already known what the informants wanted, from that need arose the wish to search for the desired information. 


\section{Conclusion}

Analysis of information literacy on diffable students based on Wilson's theory gained several conclusions. First, Analysis of information literacy found that although they have limitations (diffable) they still need information, this need makes a strong desire to seek information according to the things they need. Second, analysis of literacy in the first activation mechanism found that their motivation for the information need is to solve problems, they have limitations, sometimes they were still found to be getting things that are not good from the community, that was what causes them to stay motivated to seek information as an escape and for personal pursuits. Third, analysis of information literacy, from the condition of diffable students, it is clearly that they came from various regions in East Java. Economically, their income is not that big in each month, but from here they were still motivated to keep looking for information as a necessity. Fourth, Analysis of information literacy based on the behavior of information searches, they understand the needs they want, this is what ultimately leads to behavior of information searches. Furthermore, suggestions for further researchers or other researchers, it is hoped that the results of this study can be used as a reference or source in conducting a research related to information literacy on diffable students.

\section{Acknowledgement}

The researcher would like to say thank you for those who help in the completion of this research and article, they are the Head of the State University of Malang as the sponsor and funder of this research, Dean at Faculty of Letter of the State University of Malang, the lecturers, and the students for the support.

\section{References}

[1] Sulistyo-Basuki, Pengantar Ilmu Perpustakaan. Jakarta: Gramedia, 2001.

[2] C. V. Anunobi and O. K. Udem, "Information Literacy Competencies: A Conceptual Analysis," J. Appl. Inf. Sci. Technol., vol. 7, no. 2, 2014, doi: 10.31229/osf.io/bsza6.

[3] P. L. Pendit and T. D. Wilson, "Perilaku Informasi , Semesta Pengetahuan," J. Doc., 1981.

[4] Wilson, "Model in Information Behaviour Research." Journal of Documentation, pp. 259 - 270, 1999, [Online]. Available: http://www2.hawaii.edu/ donnab/lis610/TDWilson_Only_1999.pdf.

[5] A. Maftuhin, "Mengikat Makna Diskriminasi: Penyandang Cacat, Difabel, dan Penyandang Disabilitas," Inklusi, vol. 3, no. 2, pp. 139-162, 2016, doi: 10.14421/ijds.030201.

[6] The SMERU Research institute, "ANNUAL REPORT 2019," 2019. [Online]. Available: https://smeru.or.id/sites/default/files/publication/ar2019_en.pdf.

[7] M. Ishtiaq, "Book Review Creswell, J. W. (2014). Research Design: Qualitative, Quantitative and Mixed Methods Approaches (4th ed.). Thousand Oaks, CA: Sage," English Lang. Teach., vol. 12, no. 5, p. 40, 2019, doi: 10.5539/elt.v12n5p40.

[8] Al-Suqri \& Al-Saufi, Information Seeking Behavior And Technology Adoption: Theories And Trends. Oman: Igi Global, 2015. 